\title{
Tailoring Selective Laser Melting Process Parameters for NiTi Implants
}

\author{
Therese Bormann, Ralf Schumacher, Bert Müller, Matthias Mertmann, and Michael de Wild
}

(Submitted March 17, 2012; in revised form July 5, 2012)

\begin{abstract}
Complex-shaped NiTi constructions become more and more essential for biomedical applications especially for dental or cranio-maxillofacial implants. The additive manufacturing method of selective laser melting allows realizing complex-shaped elements with predefined porosity and three-dimensional micro-architecture directly out of the design data. We demonstrate that the intentional modification of the applied energy during the SLM-process allows tailoring the transformation temperatures of NiTi entities within the entire construction. Differential scanning calorimetry, x-ray diffraction, and metallographic analysis were employed for the thermal and structural characterizations. In particular, the phase transformation temperatures, the related crystallographic phases, and the formed microstructures of SLM constructions were determined for a series of SLM-processing parameters. The SLM-NiTi exhibits pseudoelastic behavior. In this manner, the properties of NiTi implants can be tailored to build smart implants with pre-defined microarchitecture and advanced performance.
\end{abstract}

Keywords biomaterials, graded properties, mechanical testing, metallography, NiTi, pseudoelasticity, selective laser melting

\section{Introduction}

Laser-based additive manufacturing processes such as selective laser melting (SLM) allow for the straightforward fabrication of metallic parts with complex three-dimensional architectures directly out of powder (Ref 1). For SLM fabrication, a CAD model of the intended part is virtually cut into horizontal slices of typically $30-100 \mu \mathrm{m}$ thickness. During the manufacturing process, a focused laser beam transmits the contour information of each virtual slice into the bed of metallic powder, which locally melts and solidifies. After scanning of one slice, the building platform is lowered about the slice thickness and re-coated by powder. The scanning of each subsequent slice by the laser and re-coating of the platform is

This article is an invited paper selected from presentations at the International Conference on Shape Memory and Superelastic Technologies 2011, held November 6-9, 2011, in Hong Kong, China, and has been expanded from the original presentation.

Therese Bormann, Institute for Medical and Analytical Technologies, University of Applied Sciences Northwestern Switzerland, Gründenstrasse 40, 4132 Muttenz, Switzerland; and Biomaterials Science Center, University of Basel, c/o University Hospital Basel, 4031 Basel, Switzerland; Ralf Schumacher and Michael de Wild, Institute for Medical and Analytical Technologies, University of Applied Sciences Northwestern Switzerland, Gründenstrasse 40, 4132 Muttenz, Switzerland; Bert Müller, Biomaterials Science Center, University of Basel, c/o University Hospital Basel, 4031 Basel, Switzerland; and Matthias Mertmann, Memry $\mathrm{GmbH}$, Am Kesselhaus 5, 79576 Weil am Rhein, Germany. Contact e-mail: michael.dewild@fhnw.ch. repeated until all slices have been processed. The part is attached to the building platform via support-structures and can be removed from the machine directly after part completion. A more detailed description of the SLM fabrication process can be found in literature ( $\operatorname{Ref} 2)$. As the preparation is simple and fast compared to conventional production methods like turning and milling, the SLM process allows fabricating patientspecific implants including dental and cranio-maxillofacial solutions for patients with special anatomical characteristics (Ref 3). In addition to dense constructions, filigree scaffold geometries with struts as small as $200 \mu \mathrm{m}$ in diameter can be manufactured, impossible to do so with conventional mechanical machining. Hence, the generative process of SLM permits the realization of open porous structures to meet specific demands. To optimize, for example, osseointegration of bone implants, pore sizes and shapes, size distributions, and gradients have to be tailored (Ref 4). With fabrication methods, like CVD coating of vitreous carbon scaffolds (Ref 5), selfpropagating high-temperature synthesis (Ref 6), or placeholder methods (Ref 7-9), the fabrication of such entities with micrometer precision is impossible. By SLM, the mechanical properties of porous bone scaffolds can be adjusted to the biomechanical needs by controlling lattice geometry, strut size, and porosity. Bone scaffolds should be further optimized by a local adaptation of scaffold architecture to the anisotropic and mechanical properties of the hard tissue (Ref 10). Implants with reduced stiffness, for example, facilitate physiological load transfer and reduce the risk of stress shielding (Ref 11).

For example, besides well-established steel, aluminum, and titanium, NiTi was recently successfully processed using SLM and laser-engineered net shaping (Ref 12-19). As a biocompatible, FDA-approved material (Ref 20), which exhibits superelasticity, shape memory effects, and high damping capacities, NiTi is a promising candidate for medical implants with extraordinary performance. Furthermore, the remarkable difference between the Young's moduli of the austenite and the martensite enables the realization of relatively soft implants 
with properties close to bone (Ref 21). As shown previously (Ref 15, 22), we successfully built complex NiTi-structures with shape memory properties. In the present article, we report on SLM fabrication of dense NiTi products with intentionally modified thermo-mechanical properties by altering the applied laser energy density. In this manner, biomimetic NiTi implants with anisotropic, gradually changing thermo-mechanical properties can be built.

\section{Experimental Procedure}

\subsection{Specimen Preparation}

Cylindrical specimens with diameters of 5 and $7 \mathrm{~mm}$ and height of $15 \mathrm{~mm}$ were produced in a vertical direction from pre-alloyed NiTi-powder (MEMRY GmbH, Weil am Rhein, Germany) by the SLM-Realizer 100 (SLM-Solutions, Lübeck, Germany). The powder with a $D_{50}$ value of $60 \mu \mathrm{m}$ was produced by gas atomization from starting material with a nominal Ni-content of $56.1 \mathrm{wt} \%$. Particle size analysis was done by laser diffraction (HELOS/BR, Sympatec GmbH, Clausthal-Zellerfeld, Germany). The cylinders were fabricated by four sets of processing parameters. Laser power and scanning velocity were varied from 60 to $80 \mathrm{~W}$ and from 171 to $133 \mathrm{~mm} / \mathrm{s}$, respectively. This choice resulted in energy densities of $60,70,84$, and $100 \mathrm{~J} / \mathrm{mm}^{3}$. As given by Eq 1, the energy density $E_{\mathrm{v}}$ depends on the laser power $P$, the scanning velocity $v$, the spacing between laser vectors $h$, and the layer thickness $d$. Equation 1 estimates the overall energy input into the powder-bed during SLM processing (Ref 23).

$E_{\mathrm{v}}=\frac{P}{h \cdot d \cdot v}$

The powder layer thickness in the experiments was set to $d=50 \mu \mathrm{m}$. The laser vector spacing for the hatch was $h=120 \mu \mathrm{m}$. Subsequent to SLM fabrication, the specimens were removed from the building platform and cut transversally into three parts using a low-speed diamond saw (IsoMet ${ }^{\circledR}$, Buehler). One part of each was kept for investigating as-built specimens ("SLM"). The second part was solution annealed at a temperature of $800{ }^{\circ} \mathrm{C}$ for a period of $30 \mathrm{~min}$ and subsequently water-quenched. The last specimen part was annealed at a temperature of $500{ }^{\circ} \mathrm{C}$ for a period of $20 \mathrm{~min}$ followed by slow cooling. In addition to the cylinders, tensile test specimens according to shape $D$ specified in the DIN 50125 (Ref 24) were manufactured with the processing parameter set corresponding to $70 \mathrm{~J} / \mathrm{mm}^{3}$. SLM processing and heat treatments took place under protective $\mathrm{Ar}$ atmosphere.

Data on transformation temperatures as presented in Fig. 1 and 2 include measurements on cylinders 5 and $7 \mathrm{~mm}$ in diameter. The measurements of cylinders with $5 \mathrm{~mm}$ in diameter annealed at $500{ }^{\circ} \mathrm{C}$ were skipped, because the cooling rates in this case during furnace cooling were not reproducible enough.

\subsection{Specimen Characterization}

The phase transformation temperatures for martensite start $\left(M_{\mathrm{s}}\right)$, martensite peak $\left(M_{\mathrm{p}}\right)$, martensite finish $\left(M_{\mathrm{f}}\right)$, austenite start $\left(A_{\mathrm{s}}\right)$, austenite peak $\left(A_{\mathrm{p}}\right)$, and austenite finish $\left(A_{\mathrm{f}}\right)$ were determined using differential scanning calorimetry (DSC, DSC

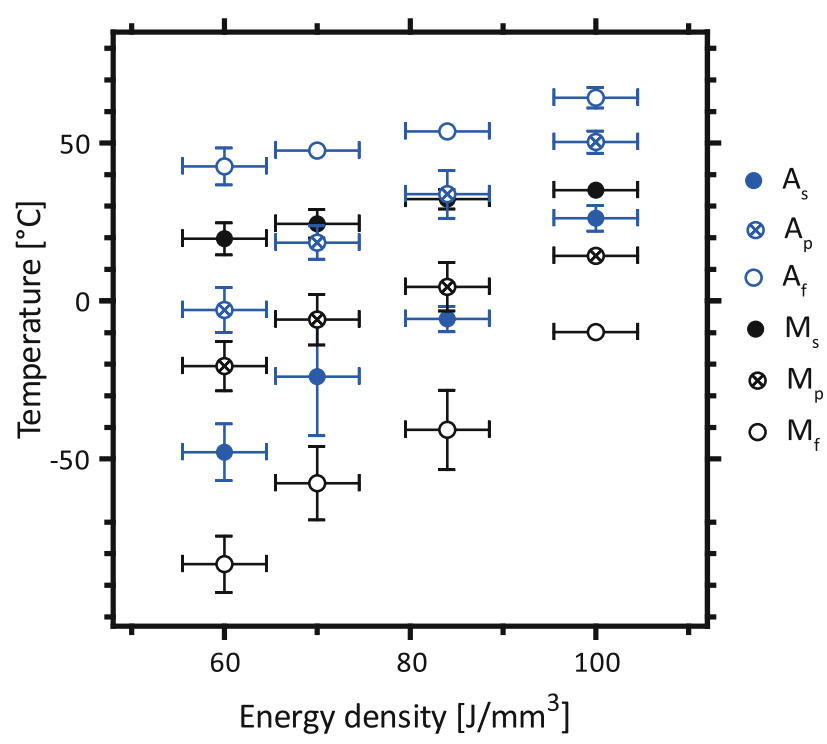

Fig. 1 Phase transformation temperatures of SLM-specimens fabricated with different energy densities

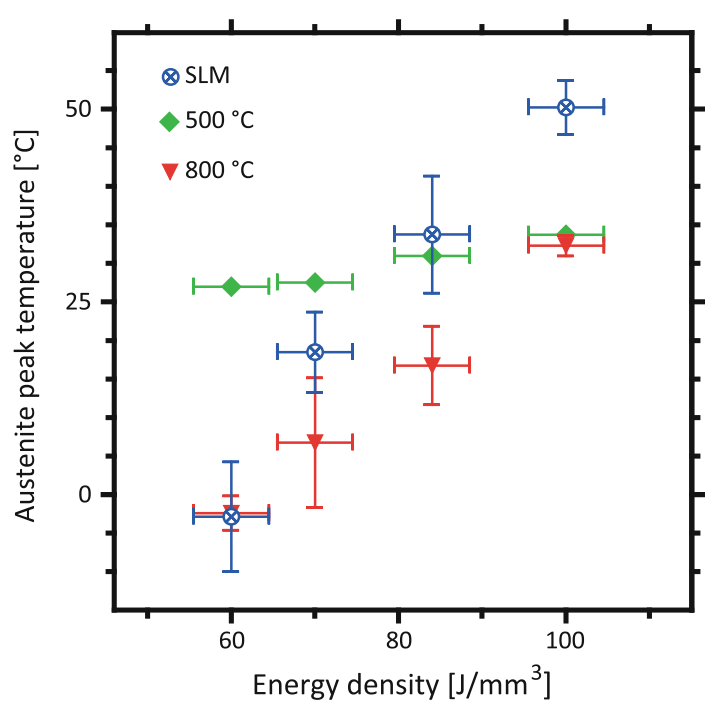

Fig. 2 Austenite peak temperatures for as-built and heat-treated SLM-specimens fabricated with different energy densities. Heat treatments were done at $800{ }^{\circ} \mathrm{C}$ and $500{ }^{\circ} \mathrm{C}$

30 , Mettler-Toledo) in the temperature range between +100 and $-125^{\circ} \mathrm{C}$ with heating and cooling rates of $10 \mathrm{~K} / \mathrm{min}$. X-ray diffraction (XRD) was carried out on the specimens $7 \mathrm{~mm}$ in diameter with grinded and electro-polished surfaces (details see below) using the D2-Phaser system (Bruker, Karlsruhe, Germany) equipped with a Co $\mathrm{x}$-ray tube $\left(\mathrm{K}_{\alpha}\right.$-radiation, $\lambda=1.78897 \AA$ ). The temperature during XRD measurements was about $32{ }^{\circ} \mathrm{C}$. Before the XRD investigations, specimens were heated above $A_{f}$ to ensure a well-defined primarily austenitic sample state.

The oxygen contents of the as-built and annealed specimens were measured by the inert gas fusion method (Galileo G8, Bruker, Karlsruhe, Germany). Before analyzing the oxygencontent, we removed the oxide surface layer by means of mechanical grinding and electro-polishing. Position-controlled tensile testing was performed in cyclic manner at room 

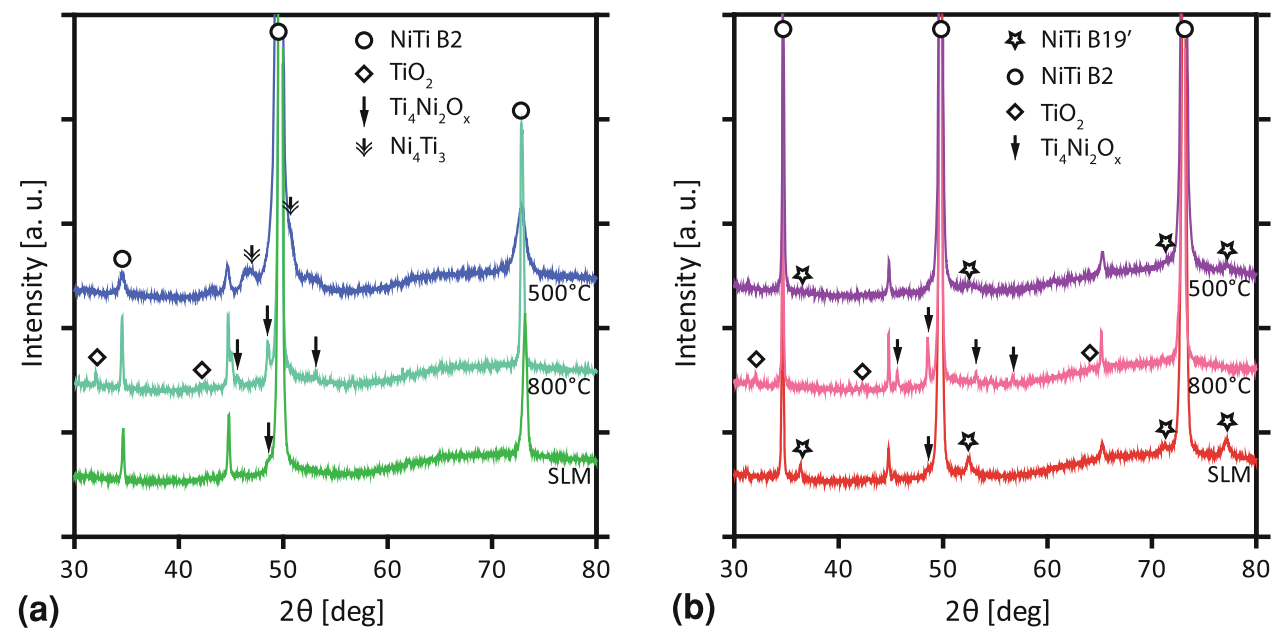

Fig. 3 XRD patterns of SLM-specimens in as-built and annealed conditions. (b) specimens built using an energy density of $100 \mathrm{~J} / \mathrm{mm}^{3}$

temperature with a constant testing speed of $0.25 \mathrm{~mm} / \mathrm{min}$ by means of a universal testing machine (Z100, Zwick/Roell, Ulm, Germany). Again, we heated the specimen before cyclic tensile testing above $A_{\mathrm{f}}$ to ensure a primarily austenitic sample state. The preparation procedure for the microstructural investigations by optical microscopy included grinding (MetaServ ${ }^{\circledR}$, Buehler), polishing with colloidal $\mathrm{SiO}_{2}$-solution (Mastermet ${ }^{\circledR}$, Buehler), and electro-polishing using a voltage of $20 \mathrm{~V}$ and a temperature of $22{ }^{\circ} \mathrm{C}$ for a period of $30 \mathrm{~s}$ with final etching during $60 \mathrm{~s}$. The electrolyte for electro-polishing consisted of $3 \mathrm{M} \mathrm{H}_{2} \mathrm{SO}_{4}$ in 1:1 ethanol-methanol ( $\mathrm{Ref} 25)$ and the chemical etchant of distilled water, $\mathrm{HCl}, \mathrm{Na}_{2} \mathrm{~S}_{2} \mathrm{O}_{5}, \mathrm{~K}_{2} \mathrm{~S}_{2} \mathrm{O}_{5}$, and $\mathrm{NH}_{4} \mathrm{HF}$, according to Escher and Hühner (Ref 26).

\section{Results and Discussion}

\subsection{Characterization of Phase Transformation Temperatures}

The SLM processing parameters determine the phase transformation temperatures as displayed in Fig. 1. The stepwise variation of the energy density between 60 and $100 \mathrm{~J} / \mathrm{mm}^{3}$ led to an increase of the transformation temperatures of up to $75 \mathrm{~K} . A_{\mathrm{s}}$, for example, increased from -50 to $25{ }^{\circ} \mathrm{C}$. Figure 2 presents the austenite peak temperatures of the as-built and annealed specimens. In specimens solution annealed at $800{ }^{\circ} \mathrm{C}$, we still found increased transformation temperatures with rising energy densities. Nevertheless, the austenite peak temperatures of the specimens produced with 70,84 , and $100 \mathrm{~J} / \mathrm{mm}^{3}$ shifted about $12-18 \mathrm{~K}$ toward lower values. After annealing at $500{ }^{\circ} \mathrm{C}$, the austenite peak temperatures leveled off at about $30^{\circ} \mathrm{C}$. Only a slight variation of about $5 \mathrm{~K}$ was detected among the specimens. The error bars for the energy density in Fig. 1 and 2 are caused by variations in layer thickness and laser power during processing.

\subsection{XRD Study}

Figure 3 shows the XRD patterns for specimens prepared with energy densities of $70 \mathrm{~J} / \mathrm{mm}^{3}$ (a) and of $100 \mathrm{~J} / \mathrm{mm}^{3}$ (b). The as-built specimens exhibit mainly peaks of the austenite phase B2. The small peak at $2 \theta=48.5^{\circ}$ reflects the presence of $\mathrm{Ti}_{4} \mathrm{Ni}_{2} \mathrm{O}_{x}$ and/or $\mathrm{Ti}_{2} \mathrm{Ni}$. No differences in terms of precipitates and impurities were found in the as-built specimens. The asbuilt specimen prepared with $100 \mathrm{~J} / \mathrm{mm}^{3}$ represents additional peaks at $36.4^{\circ}, 52.5^{\circ}, 71.4^{\circ}$, and $77.3^{\circ}$ marked by stars in Fig. 3(b), which arise from the martensite phase B19'. The martensite phase originates from the phase transformation $\mathrm{B} 2 \rightarrow \mathrm{B} 19^{\prime}$, which starts at the temperature $M_{\mathrm{s}}=35^{\circ} \mathrm{C}$. Note that XRD investigations were carried out at $\sim 32^{\circ} \mathrm{C}$. The reflections at $44.7^{\circ}$ and $65.3^{\circ}$ could not definitely be identified; possibly they refer to elemental titanium. Besides, from SLM specimens, both peaks are present in powder and starting material before atomization (data not shown), i.e., they do not refer to precipitates or impurities caused by SLM fabrication.

XRD investigations of specimens annealed at $800{ }^{\circ} \mathrm{C}$ show the formation of Ti-rich phases. The reflections at $32.0^{\circ}, 42.2^{\circ}$, and $64.1^{\circ}$, marked by open diamonds in Fig. 3, refer to $\mathrm{TiO}_{2}$, while the reflections at $45.6^{\circ}, 48.5^{\circ}$, and $53.1^{\circ}$ marked by arrows, refer to $\mathrm{Ti}_{2} \mathrm{Ni}$ and oxygen-rich inclusions like $\mathrm{Ti}_{4} \mathrm{Ni}_{2} \mathrm{O}_{x}$. As we detected oxygen contents of $(0.102 \pm 0.019) \mathrm{wt} . \%$ in asbuilt, of $(0.101 \pm 0.005)$ wt. $\%$ in $500{ }^{\circ} \mathrm{C}$ annealed and of $(0.118 \pm 0.003)$ wt. $\%$ in $800{ }^{\circ} \mathrm{C}$ annealed specimens (Ref 22), the oxygen content increased by about $0.02 \mathrm{wt} \%$ after solution annealing. One can, therefore, reasonably assume that the reflections at $45.6^{\circ}, 48.5^{\circ}$, and $53.1^{\circ}$ rather originate from $\mathrm{Ti}_{4} \mathrm{Ni}_{2} \mathrm{O}_{x}$ than from $\mathrm{Ti}_{2} \mathrm{Ni}$.

The phase transformation temperatures in Ni-rich NiTi, as is well known, depend on the Ni/Ti ratio (Ref 27, 28). Ni-loss leads to an increase, whereas Ti-loss leads to a decrease of the transformation temperatures. As no evidence for Ni-consuming phases could be found in the as-built and the $800{ }^{\circ} \mathrm{C}$-treated specimens, we hypothesize that $\mathrm{Ni}$ evaporated during the processing causing the increased transformation temperatures with applied energy density. This hypothesis is in accordance with findings of Meier et al. (Ref 12). Two explanations can be used to understand the decrease in phase transformation temperatures after $800{ }^{\circ} \mathrm{C}$ annealing. First, the formation of Ti-rich impurities during solution annealing (cp. Fig. 3) leads to Ti-reduction in the NiTi-matrix, which reduces the transformation temperatures. Secondly, $\mathrm{Ni}_{4} \mathrm{Ti}_{3}$-precipitates in quantities below the detection limit of XRD were formed during SLM 

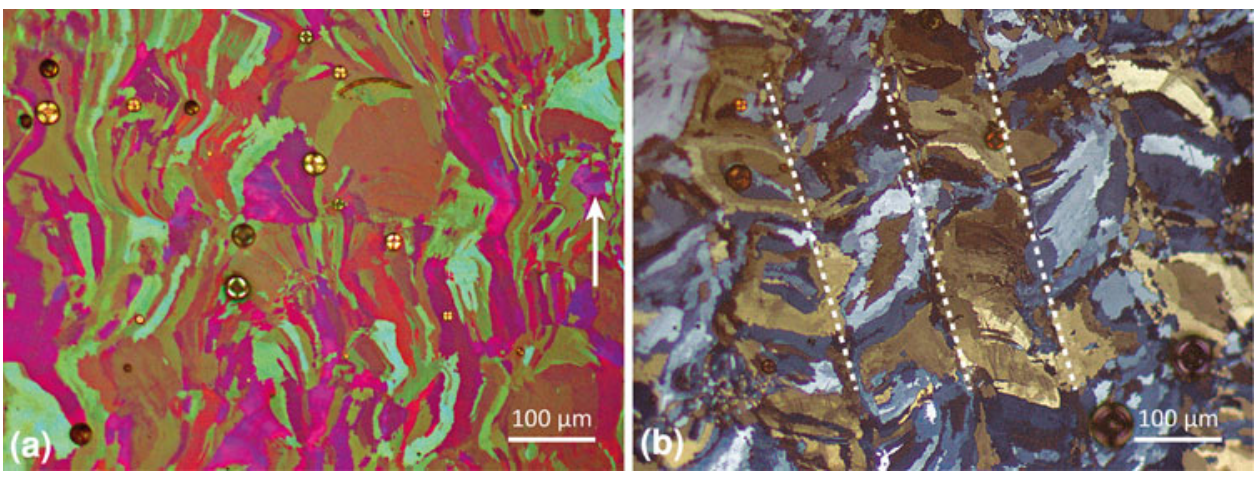

Fig. 4 Optical micrographs of SLM-NiTi. (a) Image along building direction (indicated by arrow). (b) Image perpendicular to the building direction. The laser paths are indicated by dotted lines

processing - in addition to the evaporation of Ni. Their dissolution during solution annealing results in an increased Ni-content in the NiTi-matrix, which would also lead to decreasing transformation temperatures. Both mechanisms may coexist. Because the $\mathrm{Ti}_{4} \mathrm{Ni}_{2} \mathrm{O}_{x}$-reflections developed in the XRD-patterns, their amount must be considerably high. Consequently, the first explanation should be dominant.

Further work is required to fully uncover the mechanisms of impurity formation during SLM fabrication and annealing processes and their influence on the phase transformation temperatures. Usage of a vacuum-furnace might be beneficial in avoiding the formation of Ti-rich impurities during solution annealing.

The increase of the transformation temperatures of the 60 and $70 \mathrm{~J} / \mathrm{mm}^{3}$ specimens, which were annealed at $500{ }^{\circ} \mathrm{C}$, is caused by the formation of $\mathrm{Ni}$-rich $\mathrm{Ni}_{4} \mathrm{Ti}_{3}$-precipitates detected by means of XRD analysis (see Fig. 3(a), reflections marked by double-lined arrows). In specimens prepared at 84 and $100 \mathrm{~J} / \mathrm{mm}^{3}$ and annealed at $500{ }^{\circ} \mathrm{C}$, the transformation temperatures did not increase. Consequently, XRD investigations did not show $\mathrm{Ni}_{4} \mathrm{Ti}_{3}$-precipitates. This is in accordance with the higher transformation temperatures (in the as-built state) and the reduced Ni-content in the NiTi-matrix, respectively, as more Ni should have evaporated at elevated energy densities and the formation of $\mathrm{Ni}_{4} \mathrm{Ti}_{3}$-precipitates is known to occur only in $\mathrm{NiTi}$ exceeding a nominal Ni-content of 50.5 at.\% and $55.57 \mathrm{wt} . \%$, respectively (Ref 29).

\subsection{Microstructure}

Metallographic analysis on specimens produced at $70 \mathrm{~J} / \mathrm{mm}^{3}$ revealed columnar grains with lengths up to several hundred micrometers (see Fig. 4(a)), which proceed along several powder layers. The grains are oriented in building direction because of epitaxial growth in the direction of heat transfer (Ref 30$)$. In cross sections perpendicular to the building direction, we found elongated, platelet-shaped grains that extend to $150 \mu \mathrm{m}$ (see Fig. 4 (b)). Their arrangement refers to the alternating laser route with a vector spacing of $120 \mu \mathrm{m}$, as indicated in Fig. 4 (b). A broad size distribution of the grains is observed. Similar anisotropic microstructure caused by SLM fabrication have been reported, e.g., for TiAl6V4 (Ref 30) and TiAl6Nb7 (Ref 31).

\subsection{Mechanical Characterization}

Figure 5 displays three cyclic tensile tests of a selected specimen produced at $70 \mathrm{~J} / \mathrm{mm}^{3}$. At room temperature, the specimen was basically in austenitic state, but since $M_{\mathrm{s}}$ was

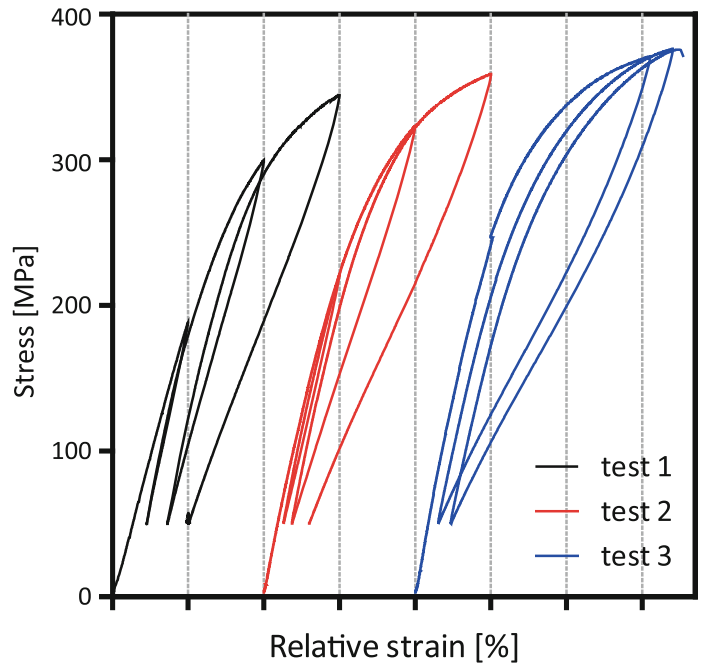

Fig. 5 Loading-unloading cycles of an SLM tensile test specimen produced with an energy density of $70 \mathrm{~J} / \mathrm{mm}^{3}$. Each increment on the $x$-axis represents $1 \%$ relative strain

approximately $25{ }^{\circ} \mathrm{C}$, also the martensitic phase was expected. The load-relief curves show clearly the characteristic pseudoelastic behavior. Note that the specimen was in the as-built condition, i.e., no additional heat treatment was applied. From Fig. 5, it is apparent that the first cycle exhibited a residual deformation of about $0.7 \%$ strain after maximal straining to $3 \%$. As the sample was kept at a minimum stress of $50 \mathrm{MPa}$, we derived the plastic deformation by extrapolating the relief curve to $\sigma=0 \mathrm{MPa}$. Martensite de-twinning most probably caused the residual strain of $0.7 \%$ after the first cycle. After straining the specimen for a second time to $3 \%$, we calculated only $0.2 \%$ deformation after specimen relief, which shows that nearly the entire martensite were de-twinned already during the first cycle. In the third cycle, the specimen was strained up to $3.4 \%$, whereupon we detected a complete shape recovery.

Further, to evaluate the pseudoelastic properties at higher strain levels, improvement of the mechanical properties of specimens in SLM tensile testing is necessary, as our specimens fail usually at around $4 \%$ strain.

\subsection{Varying Processing Parameters Within One Construct}

As the processing parameters influence the phase transformation temperatures, we conducted preliminary experiments on 
Table 1 Difference in transformation temperatures of specimens produced with two distinct sets of process parameters (cp. scheme); $\Delta T$ represents the difference between upper and lower entities

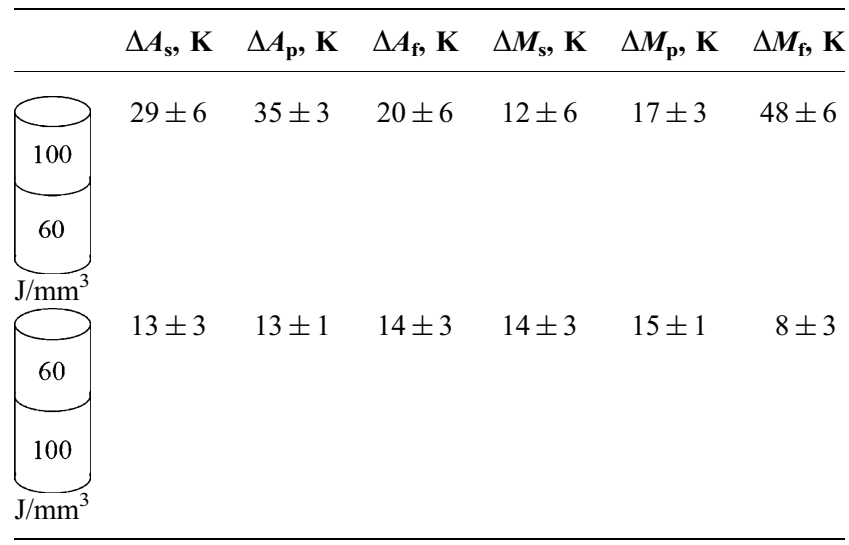

NiTi specimens consisting of two regions built with distinct SLM parameters. As listed in Table 1, lower and upper parts of cylindrical specimens were produced with 100 and 60 or 60 and $100 \mathrm{~J} / \mathrm{mm}^{3}$, respectively. The processing by varying SLM parameters led to NiTi-parts with regions of different phase transformation temperatures. Differences in the observed phase transformation temperatures are summarized in Table 1. This difference, however, is smaller than expected from the experiments presented above, in which differences of up to $75 \mathrm{~K}$ were detected. The entities prepared with $60 \mathrm{~J} / \mathrm{mm}^{3}$ show considerable differences in their transformation temperatures, possibly caused by modified cooling rates within the specimens during the building process. For a better control, further dependencies of transformation temperatures on the process parameters have to be examined.

\section{Conclusions}

Using different sets of process parameters, the phase transformation temperatures of SLM built NiTi entities can be directly tailored. The reason behind is most likely the Ni loss by evaporation, which increases with applied energy density. Solution annealing leads to a decrease of the phase transformation temperatures in the specimens produced with energy densities of 70,84 , and $100 \mathrm{~J} / \mathrm{mm}^{3}$, associated with the formation of Ti-rich phases including $\mathrm{Ti}_{4} \mathrm{Ni}_{2} \mathrm{O}_{x}$ and $\mathrm{TiO}_{2}$. Nevertheless, the increase in transformation temperatures with applied energy densities is preserved. After annealing at $500{ }^{\circ} \mathrm{C}$, the specimens did not show remarkable differences in their transformation temperatures anymore. Cyclic loading proved that SLM-built specimens exhibit pseudoelastic behavior directly after manufacturing, i.e., without additional heat treatments. A shape recovery of up to $3 \%$ strain was demonstrated.

The application of varied SLM process parameters, therefore, allows for the fabrication of pseudoelastic and pseudoplastic NiTi-structures from the same starting material. In addition, constructions consisting of several regions with distinct phase transformation temperatures can be built. This approach permits manufacturing implants with locally pre-defined anisotropic properties. SLM-produced implants could, for example, consist of pseudoelastic, shock-absorbing regions, on the one hand; pseudoplastic regions, on the other hand, would offer a reduced Young's modulus and the possibility to facilitate the one-way shape memory effect.

\section{Acknowledgements}

The multi-disciplinary team gratefully acknowledges the financial support of the Swiss National Science Foundation within the research program NRP 62 "Smart Materials."

\section{References}

1. I. Yadroitsev, L. Thivillon, P. Bertrand, and I. Smurov, Strategy of Manufacturing Components with Designed Internal Structure by Selective Laser Melting of Metallic Powder, Appl. Surf. Sci., 2007, 254(4), p 980-983

2. D.K. Pattanayak, A. Fukuda, T. Matsushita, M. Takemoto, S. Fujibayashi, K. Sasaki, N. Nishida, T. Nakamura, and T. Kokubo, Bioactive Ti Metal Analogous to Human Cancellous Bone: Fabrication by Selective Laser Melting and Chemical Treatments, Acta Biomater, 2010, 7(3), p 1398-1406

3. L. Mullen, R.C. Stamp, W.K. Brooks, E. Jones, and C.J. Sutcliffe, Selective Laser Melting: A Regular Unit Cell Approach for the Manufacture of Porous, Titanium, Bone In-Growth Constructs, Suitable for Orthopedic Applications, J. Biomed. Mater. Res. Part B, 2009, 89(2), p 325-334

4. F.C. Fierz, F. Beckmann, M. Huser, S.H. Irsen, B. Leukers, F. Witte, O. Degistirici, A. Andronache, M. Thie, and B. Müller, The Morphology of Anisotropic 3D-Printed Hydroxyapatite Scaffolds, Biomaterials, 2008, 29(28), p 3799-3806

5. B.R. Levine, S. Sporer, R.A. Poggie, C.J. Della Valle, and J.J. Jacobs, Experimental and Clinical Performance of Porous Tantalum in Orthopedic Surgery, Biomaterials, 2006, 27(27), p 4671-4681

6. J.S. Kim, S.H. Lee, J.H. Kang, V.E. Gjunter, S.B. Kang, T.H. Nam, and Y.S. Kwon, The Effect of Processing Variables on the Microstructure and Mechanical Property of a Porous Body Produced by the SHS Method, SMST-2000, Proceedings of SMST 2000, 2000, p 77

7. T. Imwinkelried, Mechanical Properties of Open-Pore Titanium Foam, J. Biomed Mater. Res. Part A, 2007, 81(4), p 964-970

8. A. Bansiddhi and D.C. Dunand, Shape-Memory NiTi Foams Produced by Replication of NaCl Space-Holders, Acta Biomater, 2008, 4(6), p 1996-2007

9. R. Singh, P.D. Lee, T.C. Lindley, R.J. Dashwood, E. Ferrie, and T. Imwinkelried, Characterization of the Structure and Permeability of Titanium Foams for Spinal Fusion Devices, Acta Biomater, 2009, 5(1), p 477-487

10. R. Schumacher, A. Yildiz, M. Näf, M. de Wild, and E. Schkommodau, Manipulation of the Elastic Behaviour of Artificial Titanium Bone Grafts, Eur. Cells Mater, 2011, 22(Suppl. 1), p 10

11. R. Huiskes, H. Weinans, and B. Van Rietbergen, The Relationship Between Stress Shielding and Bone Resorption Around Total Hip Stems and the Effects of Flexible Materials, Clin. Orthop. Rel. Res., 1992, 274, p 124-134

12. H. Meier, C. Haberland, J. Frenzel, and R. Zarnetta, Selective Laser Melting of NiTi Shape Memory Components, Innovative Developments in Design and Manufacturing: Advanced Research in Virtual and Rapid Prototyping, CRC Press-Taylor \& Francis Group, 2010, p 233-238

13. A.T. Clare, P.R. Chalker, S. Davies, C.J. Sutcliffe, and S. Tsopanos, Selective Laser Melting of High Aspect Ratio 3D Nickel-Titanium Structures Two Way Trained for MEMS Applications, Int. J. Mech. Mater. Des., 2008, 4, p 181-187

14. S. Dudziak, M. Gieseke, H. Haferkamp, S. Barcikowski, and D. Kracht, Functionality of Laser-Sintered Shape Memory Micro-Actuators, Laser Assisted Net Shape Engineering 6, Proceedings of the Lane 2010, Part 2, Elsevier Science Bv, 2010, p 607-615

15. T. Bormann, S. Friess, M. de Wild, R. Schumacher, G. Schulz, and B. Müller, Determination of Strain Fields in Porous Shape Memory Alloys 
Using Micro Computed Tomography, Proc SPIE, 2010, $\mathbf{7 8 0 4}$ p $78041 \mathrm{M}$

16. A. Bandyopadhyay, B.V. Krishna, W.C. Xue, and S. Bose, Application of Laser Engineered Net Shaping (LENS) to Manufacture Porous and Functionally Graded Structures for Load Bearing Implants, J. Mater. Sci. Mater. Med., 2009, 20, p 29-34

17. B.V. Krishna, S. Bose, and A. Bandyopadhyay, Laser Processing of Net-Shape NiTi Shape Memory Alloy, Metall. Mater. Trans. A Phys. Metall. Mater. Sci., 2007, 38(5), p 1096-1103

18. B.V. Krishna, S. Bose, and A. Bandyopadhyay, Fabrication of Porous NiTi Shape Memory Alloy Structures Using Laser Engineered Net Shaping, J. Biomed. Mater. Res. Part B, 2009, 89(2), p 481-490

19. H. Meier, C. Haberland, and J. Frenzel, Structural and Functional Properties of NiTi Shape Memory Alloy Produced by Selective Laser Melting, Innovative Developments in Design and Manufacturing. Advanced Research in Virtual and Rapid Prototyping, CRC PressTaylor \& Francis Group, 2012, p 291-296

20. ASTM, Standard Specification for Wrought Nickel-Titanium Shape Memory Alloys for Medical Devices and Surgical Implants, F2063, ASTM International

21. T.W. Duerig and A.R. Pelton, Ti-Ni Shape Memory Alloys, Materials Properties Handbook: Titanium Alloys, R. Boyer, G. Welsch, and E.W. Collings, Ed., ASM International, Materials Park, 1994

22. T. Bormann, R. Schumacher, B. Müller, and M. de Wild, Fabricating NiTi Shape Memory Scaffolds by Selective Laser Melting, Eur. Cells Mater., 2011, 22(Suppl. 1), p 12
23. H. Meier and C. Haberland, Experimental Studies on Selective Laser Melting of Metallic Parts, Materialwiss. Werkst., 2008, 39(9), p 665-670

24. Prüfung metallischer Werkstoffe - Zugproben, DIN 50125:2004-01, Deutsches Institut für Normung e.V

25. H. Schumann and H. Oettel, Metallografie, Wiley-VCH, Weinheim, 2005

26. K. Escher and M. Huhner, Metallographical Preparation of NiTi Shape Memory Alloys, Prakt. Metallogr., 1990, 27(5), p 231-235

27. J. Khalil-Allafi, A. Dlouhy, and G. Eggeler, $\mathrm{Ni}_{4} \mathrm{Ti}_{3}$-Precipitation During Aging of NiTi Shape Memory Alloys and its Influence on Martensitic Phase Transformations, Acta Mater., 2002, 50(17), p 4255-4274

28. J. Frenzel, E.P. George, A. Dlouhy, C. Somsen, M.F.-X. Wagner, and G. Eggeler, Influence of Ni on Martensitic Phase Transformations in NiTi Shape Memory Alloys, Acta Mater, 2010, 58, p 3444-3458

29. E. Schuller, M. Bram, H.P. Buchkremer, and D. Stover, Phase Transformation Temperatures for NiTi Alloys Prepared by Powder Metallurgical Processes, Mater. Sci. Eng. A Struct. Mater. Prop. Microstruct. Process., 2004, 378(1-2), p 165-169

30. L. Thijs, F. Verhaeghe, T. Craeghs, J.V. Humbeeck, and J.-P. Kruth, A Study of the Microstructural Evolution During Selective Laser Melting of Ti-6Al-4V, Acta Mater., 2009, 58(9), p 3303-3312

31. E. Chlebus, B. Kuznicka, T. Kurzynowski, and B. Dybala, Microstructure and Mechanical Behaviour of Ti-6Al-7Nb Alloy Produced by Selective Laser Melting, Mater. Charact., 2011, 62(5), p 488-495 